\title{
Drug Accountability Supplemental Qualifiers Dataset
}

National Cancer Institute

\section{Source}

National Cancer Institute. Drug Accountability Supplemental Qualifiers Dataset. NCI

Thesaurus. Code C147196.

A dataset containing supplemental information, specifically non-standard variables, to parent records in the drug accountability domain. 